\title{
Severe acute respiratory syndrome (SARS): a review
}

\section{Pandurangan Vijayanand, Ed Wilkins and Mark Woodhead}

Pandurangan Vijayanand MB MRCP, Specialist

Registrar*

Ed Wilkins FRCP FRCPath, Consultant Physician,

Department of Infectious

Diseases, North Manchester Geneal Hospital

Mark Woodhead BSC DM FRCP,

Consultant in

General and

Respiratory Medicine*

*Department of

Respiratory

Medicine,

Manchester Royal Infirmary

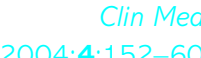

ABSTRACT - Severe acute respiratory syndrome (SARS) is a newly emerged disease that rapidly spread around the world. The disease originated in southern China and a novel coronavirus (SARS CoV) has been implicated as the causative organism. The path this virus took to set up human infection remains a mystery, though preliminary data point to origins in an animal reservoir. Nosocomial transmission of SARS CoV has been a striking feature in this epidemic. The clinical illness is similar to many acute respiratory infections, although a large proportion of patients show a rapid deterioration with respiratory distress towards the end of the second week of illness. The management principles are broadly similar to treating any community acquired pneumonia but the infection control measures take a pivotal role. There is no proven antiviral agent against SARS CoV. The most remarkable feature about the SARS epidemic was the speed with which the global community acted in a coordinated way to control it.

KEY WORDS: community acquired pneumonia, coronavirus, epidemic, SARS, SARS CoV, severe acute respiratory syndrome

Severe acute respiratory syndrome (SARS) is a recently emerged human disease associated with pneumonia. This disease was first recognised in Guangdong Province, China, in November 2002. ${ }^{1}$ Subsequent to its introduction to Hong Kong in mid-February 2003, the virus spread to more than

\section{Key Points}

SARS is a 'new' human respiratory disease, first encountered in 2002 , and is caused by a newly identified coronavirus

The origin of the infection is probably in animals, but the infection is transmissible between humans, which led to rapid spread to over 8,000 people

A significant proportion of those affected were healthcare personnel

Treatment is supportive, as no effecive antiviral treatment has yet been identified

The epidemic was halted by infection control procedures, but it may reemerge in the future

30 countries causing disease in over 8,000 patients across five continents. Through a massive worldwide response coordinated by the World Health Organization (WHO), SARS was successfully contained in less than four months. ${ }^{2}$ Much has been learned about this syndrome since March 2003, including its causation by a new coronavirus (SARS CoV), but our knowledge about SARS coronavirus infection remains limited. The WHO warns that resurgence of SARS remains a distinct possibility and does not allow for complacency.

\section{History}

Plagues are as certain as death and taxes. ${ }^{3}$ Over the last century several important human microbes causing severe acute respiratory disease have emerged (Table 1). SARS CoV is not the first, and nor will it be the last of its kind. All these infections, with the exception of Legionnaires' disease, have one thing in common: the origin of the infective agent is in animals, either domestic or wild. Chlamydia pneumoniae and human metapneumovirus are examples of other new pathogens causing severe acute respiratory illness in which humans have always been the likely host. The source of SARS CoV remains to be determined.

When reports of a mysterious respiratory illness began to emerge from southern China in late 2002, no one knew what caused it. Would history be repeated with a strain as deadly as the 1918 pandemic strain which killed up to 40 million people? Was this caused by a supervirulent strain of flu, as seemed to be suggested by the coincidence of two deaths due to H5N1 influenza? Even in mid-March, when outbreaks elsewhere in Asia caused the WHO to release its first ever global alert that shot SARS on to the world's news agenda, the pathogen remained unknown. ${ }^{1}$ The infectiousness of the disease, its mode of transmission and death rate were also unclear. Health officials were not sure whether they were dealing with a troubling, but ultimately limited, threat or a global mass killer. ${ }^{4}$

The earliest cases are now known to have occurred in mid-November 2002 in Guangdong Province, China. SARS was carried out into the world at large on 21 February 2003 when an infected medical doctor from Guangdong checked into a ninth floor room of a Hong Kong hotel. That single hotel floor 
Table 1. History of epidemics over the last century.

\begin{tabular}{ll}
\hline Year & Outbreak \\
\hline 1918 & Great flu pandemic, worldwide \\
1976 & Legionnaires' disease, Philadelphia, USA \\
1993 & Hanta virus pulmonary syndrome, USA \\
1994 & Hendra virus infection, Australia \\
1997 & H5N1 influenza infection, Hong Kong \\
1999 & Nipah virus encephalitis/pneumonitis, Malaysia
\end{tabular}

became the setting, in ways that remain incompletely understood, for the international spread of SARS. ${ }^{5}$ At least 14 hotel guests and visitors carried the virus with them to the hospital systems of Hong Kong, Toronto, Vietnam and Singapore and triggered severe outbreaks. Hospital staff responding to the earliest cases failed to protect themselves from infection as the risks of transmission were unknown. As a result, the disease rapidly spread within hospitals, infecting staff, other patients and visitors, and then spilled out into the larger community as family members and their close contacts became infected.

\section{Aetiology}

Although SARS currently has no absolutely confirmed cause, a first approximation of Koch's postulates has been satisfied for a newly discovered virus within the family Coronaviridae: ${ }^{6}$

- Oropharyngeal specimens from patients with SARS induced a cytopathic effect on Vero E6 tissue culture cells.

- Electron microscopic examination of cultures revealed ultrastructural features characteristic of coronaviruses.

- Immunohistochemical and immunofluorescence staining revealed reactivity with group I coronavirus polyclonal antibodies.

- Consensus coronavirus primers designed to amplify a fragment of the polymerase gene by reverse transcriptase-polymerase chain reaction (RT-PCR) were used to obtain a sequence that identified the isolate as a unique coronavirus only distantly related to previously sequenced coronaviruses.

- PCR methods detected the SARS virus in clinical samples from affected patients in diverse geographical locations.

- Serological evidence has shown the presence of antibodies specific to the new coronavirus in the serum of patients with SARS. $^{6-11}$

- In experimental animal studies, infection of cynomolgus macaques (Macaca fascicularis) with SARS CoV resulted in pneumonia and necropsy proven pulmonary damage similar to that seen in human beings with SARS. ${ }^{12}$

Collectively, these data strongly implicate this newly identified coronavirus SARS CoV as the cause of SARS.

Coronaviruses are large enveloped viruses with a positive stranded RNA genome ranging in size from 27 to $30 \mathrm{~kb}$, the largest of any of the RNA viruses. In humans, coronaviruses are usually associated with the common cold but in animals they can lead to highly virulent respiratory, enteric and neurological diseases as well as hepatitis.

Analysis of the complete genome sequence of SARS CoV published in May 2003 suggests that it is not closely related to any of the three previously identified coronavirus subfamilies, nor does it seem to have arisen through a chance genetic recombination between known coronaviruses. ${ }^{13}$ Its unique sequence suggests that it has evolved independently from other members of the family, probably in an animal host. ${ }^{14,15}$

\section{Epidemiology}

The SARS coronavirus is believed to have jumped from an animal host to people in the animal markets in towns in the Guangdong province of southern China. The path the virus took to set up human infection - essential information for assessing the likelihood of recurrence - remains a mystery.

Knowledge of the chains of animals involved in transmitting the SARS virus to humans would help in the design of preventive measures. For example, when the Nipah virus epidemic began causing fatal encephalitis in livestock and people in Malaysia in 1998, about one million pigs were slaughtered. Later, when the natural reservoir of the virus was found to be fruit bats, farmers could take measures to isolate their livestock from bats; this eventually led to the control of that epidemic. ${ }^{16}$

The early cases of SARS in Guangdong province reportedly occurred in restaurant workers handling wild animals as exotic food, ${ }^{17}$ so attention was focused on wild animals recently captured and marketed for culinary purposes. Researchers from the University of Hong Kong examined 25 animals belonging to seven wild and one domestic animal species in a live animal market in southern China that supplies restaurants in Guangdong province. ${ }^{18}$ Six of the animals tested were masked palm civets (Paguma larvata) (which look like long-nosed cats); four of these, which came from several different owners and appeared healthy, tested positive for SARS-like virus. One raccoon dog (a member of the dog family native to eastern Asia) was tested and found to have the virus in faeces. Sera from three animal species, the palm civets, raccoon dog and a Chinese ferret badger, had neutralising antibody to the animal coronavirus. Sera from up to $40 \%$ of the humans working in the market were also positive for the antibody. The serum from animals inhibited growth of the human SARS virus in the laboratory. Similarly, serum from people who recovered from SARS hindered growth of virus from the civets. This cross-reaction is a strong indication that these viruses are similar. Importantly, the full-length genome sequence of this animal coronavirus ( $\mathrm{S} \mathrm{CoV}$ ) had $99.8 \%$ homology to the human SARS CoV, indicating that they are closely related. The only difference is a 29 -nucleotide sequence which is not found in most human isolates. ${ }^{18}$

These findings suggest that the markets provided a venue for the animal SARS CoV-like virus to amplify and transmit to new hosts, including humans. It is not, however, clear whether any one (or more) of these animals is the natural reservoir in the 
wild. It is conceivable that civets, raccoon dogs and ferret badgers were all infected from another, as yet unknown, animal source (possibly a smaller mammal easily consumed by all three), which is possibly the true reservoir in nature. Further extensive surveillance as proposed by the $\mathrm{WHO}^{19}$ would help to understand the animal reservoir and the interspecies transmission events that led to the outbreak of SARS.

Evolution, propagation and persistence of infectious diseases in the twenty-first century is thought to be facilitated both by the ease of mobility in contemporary society, for example through air travel, and by the growth in the world population, primarily the rise in the number of densely populated urban areas, especially in Asia. The key epidemiological determinants of the magnitude and timescale of an epidemic are:

- the interval between infection and onset of symptoms

- the interval between onset and hospital admission

- the degree and duration of infectiousness of the agent

- the extent of contact and mixing between infectious and susceptible people enabling transmission of the virus

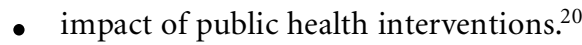

For epidemiologists, the key parameter reflecting the above is known as Ro, a measure of a disease's infectiousness. Ro corresponds to the number of people infected by each patient in the absence of public health measures. A model of the spread of SARS gave a Ro of between two and four, ${ }^{21,22}$ indicating that public health measures (eg patient isolation) would be sufficient to bring the epidemic under control. This contrasts with flu which has a Ro of about 10; in this case, quarantining those who show symptoms is not enough to bring the average number of new infections caused by each case below one, the level necessary for an epidemic to be contained.

Nosocomial transmission of SARS $\mathrm{CoV}$ has been a striking feature of the SARS outbreak, with as many as one in five of all cases being in healthcare workers. Most cases are adults, with children rarely identified. The mean incubation period is five days with a range of 2-10 days, although there are isolated reports of longer incubation periods. There have been no reports of transmission occurring before the onset of symptoms. The mean time from the onset of clinical symptoms to admission to hospital was 3-5 days, with longer times earlier in the epidemic. ${ }^{20}$ The dynamics of transmission of SARS fits with the idea that it is spread by close contact, requiring its victims to breathe in droplets of virus laden mucus - explaining why most transmission occurred in confined settings like hospitals.

A recent case control study in five Hong Kong hospitals looked at the effectiveness of precautions against the spread of SARS. It concluded that the practice of droplet and contact precaution is adequate in significantly reducing the risk of infection after exposure to SARS. ${ }^{23}$ Transmission by the faecal-oral route has also been reported in some instances. ${ }^{5}$

\section{Pathogenesis}

The histological changes of uncomplicated viral pneumonias are rarely described. Reports tend to be derived from post-mortem examination of patients who succumb to the pneumonia, and thus may not be representative of the majority of pneumonia patients who survive. The same is also true of SARS. Several distinct features of fatal coronaviral pneumonia have been identified: ${ }^{24}$

- epithelial cell proliferation

- diffuse alveolar damage

- macrophage infiltration of the lungs

- haemophagocytosis (a feature attributed to cytokine dysregulation).

These pathological features of SARS CoV pneumonia are similar to H5N1 influenza pneumonia. ${ }^{25}$ Experimental studies in

Table 2. Clinical symptoms (\%) at presentation of patients with severe acute respiratory syndrome.

\begin{tabular}{lcccc}
\hline Study & $\begin{array}{c}\text { Peiris et } \boldsymbol{l}^{29} \\
\text { (Hong Kong) }\end{array}$ & $\begin{array}{c}\text { Lee et } \boldsymbol{a l}^{32} \\
\text { (Hong Kong) }\end{array}$ & $\begin{array}{c}\text { Booth et al } \\
\text { (Canada) }\end{array}$ & $\begin{array}{c}\text { Donnelly et al } \\
\text { (Hong Kong) }\end{array}$ \\
\hline Patient numbers & 50 & 138 & 144 & 1,425 \\
Age (mean) & 43 & 39.3 & - & - \\
Fever & 100 & 100 & 85 & 94 \\
Chills or rigor & 74 & 73 & 49 & 65 \\
Myalgia & 54 & 61 & - & 51 \\
Malaise & 50 & - & 69 & 64 \\
Anorexia & 20 & - & 42 & 55 \\
Cough & 62 & 57 & - & 31 \\
Breathlessness & 20 & - & - & 27 \\
Diarrhoea & 10 & 20 & - & 25 \\
Runny nose & 24 & 22 & - & 31 \\
Sore throat & 20 & 23 & 56 &
\end{tabular}


which macrophages are infected in vitro suggest that the H5N1 influenza viruses are hyperinducers of pro-inflammatory cytokines. ${ }^{26}$ Human coronavirus can replicate in human macrophages in vitro. ${ }^{27,28}$ Taken together, it has been suggested that in SARS CoV pneumonia, pro-inflammatory cytokines released by stimulated macrophages in the alveoli have a prominent role in the pathogenesis of SARS leading to cytokine dysregulation. This idea has implications for the management of coronaviral pneumonia, as interventions with steroids might modulate this cytokine response and prevent fatal outcome. ${ }^{28}$

\section{Clinical features}

The clinical illness is like many other acute respiratory infections. Table 2 illustrates the common clinical features in different settings. ${ }^{29-34}$ The clinical progression of SARS is mostly uniform, with a biphasic pattern of illness characterised by a wave of deterioration towards the end of the second week (Table 3 ).

\section{Week 1 of illness}

Patients initially develop influenza-like prodromal symptoms. Presenting symptoms include fever, malaise, headache, and rigors. No individual symptom or cluster of symptoms has proven specific. Although history of fever is the most frequently reported symptom, it may be absent on initial measurement. ${ }^{19}$

\section{Week 2 of illness}

Cough, dyspnoea and diarrhoea may be present in the first week but are more commonly reported in the second week of illness. At this stage up to $70 \%$ of the patients develop diarrhoea, which has been described as large volume and watery without blood or mucus. ${ }^{35}$ Towards the end of the second week severe cases deteriorate, developing rapidly progressing respiratory distress with about $20 \%$ requiring intensive care. ${ }^{36}$

Laboratory findings include lymphopenia (70\%), thrombocytopenia ( $45 \%)$, elevated lactate dehydrogenase (LDH) $(70 \%)$, raised creatine kinase and alanine aminotransferase (AAT) $(30 \%)$. $^{37}$

Radiological findings in SARS are well characterised on both chest radiograph and computed tomography (CT) scan. ${ }^{38-43}$ On chest radiograph, there is predominant lower zone $(65 \%)$ and peripheral lung $(75 \%)$ involvement (Figs 1(a) and 1(b)). These changes are confirmed by high resolution CT scanning and may be seen even when the chest radiograph is normal. Lack of cavitation, lymphadenopathy and pleural effusion are typical of SARS. Other common findings include mainly ground glass opacification and sometimes consolidation, interlobular septal and intralobular interstitial thickening. The pattern of peripheral ground glass opacification is different from the
Table 3. Clinical progression of treated severe acute respiratory syndrome.

\begin{tabular}{lcc}
\hline Clinical feature & $\begin{array}{c}\text { Frequency } \\
\text { (\%) }\end{array}$ & $\begin{array}{c}\text { Mean time } \\
\text { (days) }\end{array}$ \\
\hline Recurrent fever & 85 & 9 \\
Watery diarrhoea & 73 & 8 \\
Radiological worsening & 80 & 7 \\
Worsening respiratory symptoms & 45 & 9 \\
New radiological lesions & 45 & - \\
Acute respiratory distress syndrome & 20 & Week 3
\end{tabular}

Fig 1. A 45-year-old Hong Kong resident with severe acute respiratory syndrome (SARS): (a) showing bilateral peripheral shadows; (b) after pulsed methyl prednisolone showing resolution of chest X-ray (CXR) shadowing (CXRs provided courtesy of Dr KW Tsang).
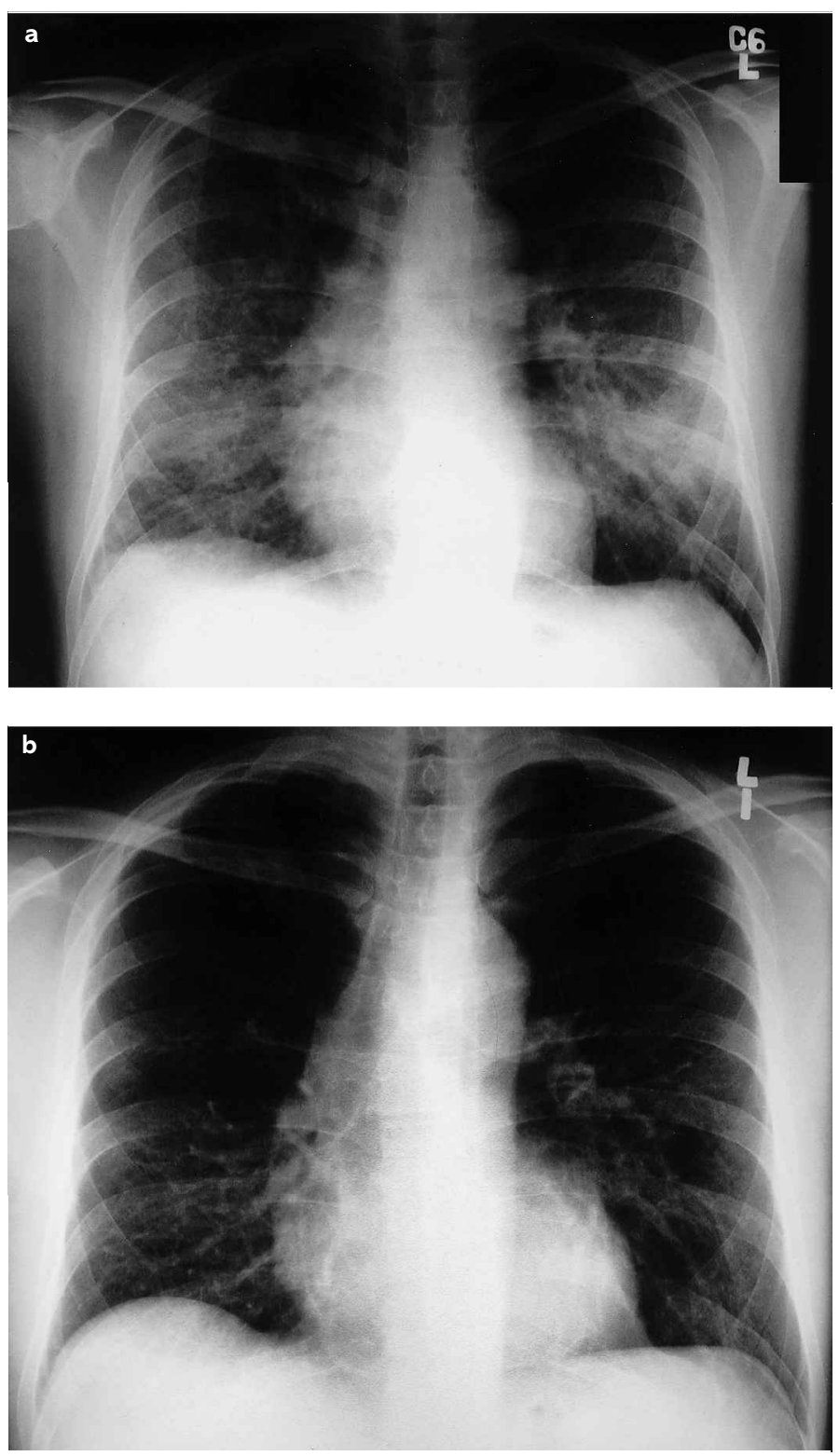
central pattern seen in atypical pneumonias caused by Mycoplasma, Chlamydia and influenza species. ${ }^{44}$

The clinical symptoms of SARS may not allow ready distinction from other common wintertime respiratory viral infections (Table 2). Certain characteristics of SARS are noteworthy: the constellation of absence of upper respiratory symptoms, the presence of dry cough and minimal auscultatory findings with consolidation on chest radiograph may alert the clinician to the possible diagnosis of SARS. However, detailed comparative studies of pneumonia with other causes are yet to be published.

Independent predictors of an adverse outcome or severe disease varied in different trials. ${ }^{45-47}$ They included:

- older age

- severe lymphopenia

- impaired AAT

- delayed starting of ribavarin and steroid

- high peak LDH

- high neutrophil count at presentation

- presence of comorbid conditions

- chronic hepatitis B virus infection.

Increasing age is a universal risk factor in all studies; this is reflected in the case fatality rate which is much lower in patients below 60 years $(13.2 \%)$ than in those over 60 years $(43 \%) .^{20}$

\section{Diagnosis}

There was a lack of reliable laboratory tests ${ }^{48}$ at the start of the epidemic, so on the basis of early findings in hospitals the WHO produced case definitions for suspected and probable cases of SARS to be used for screening patients before admission to hospital and in non-clinical contexts such as airports. Subsequent prospective validation of the WHO criteria for identifying patients only with SARS out of hospital, in a screening clinic in Hong Kong, showed a sensitivity of only $26 \%$ and specificity of $96 \% .^{49}$ This highlights the limitations of the current WHO guidelines. The authors suggest that daily follow-up, evaluation of non-respiratory systemic symptoms and chest radiography may be better screening tools. The latest WHO case definitions are summarised in Table 4.

Finally, it is important to identify other common microbial causes of community-acquired pneumonia (CAP) by appropriate tests. Co-infection with SARS and conventional respiratory pathogens does occur, so the finding of another microbial cause does not exclude SARS.

\section{Management}

Guidelines for the management of SARS have been produced. The principles of its management are listed in Table $5 .{ }^{50}$ Broadly

Table 4. World Health Organization case definitions of severe acute respiratory syndrome (SARS) patients (adapted from Refs 19 and 49).

$\begin{array}{ll}\text { Clinical case definition } & \text { A person with a history of: } \\ \text { of SARS } & \text { Fever }\left(>38^{\circ} \mathrm{C}\right) \\ & \text { and One or more symptoms of lower respiratory tract illness (cough, } \\ & \text { difficulty breathing, shortness of breath) } \\ & \text { and Radiological evidence of lung infiltrates consistent with pneumonia } \\ & \text { or RDS or autopsy findings consistent with the pathology of pneumonia } \\ & \text { or RDS without an identifiable cause } \\ & \text { and No alternative diagnosis can fully explain the illness }\end{array}$

Laboratory case definition of SARS
A person with symptoms and signs that are clinically suggestive of SARS and with positive laboratory findings for SARS CoV based on one or more of the following diagnostic criteria:

(a) PCR positive for SARS CoV

PCR positive using a validated method from:

- At least two different clinical specimens (eg nasopharyngeal and stool) or

- The same clinical specimen collected on two or more occasions during the course of the illness (eg sequential nasopharyngeal aspirates) or

- Two different assays or repeat PCR using a new RNA extract from the original clinical sample on each occasion of testing

(b) Seroconversion by ELISA or IFA

- Negative antibody test on acute serum followed by positive antibody test on convalescent phase serum tested in parallel or

- Fourfold or greater rise in antibody titre between acute and convalescent phase sera tested in parallel

(c) Virus isolation

- Isolation in cell culture of SARS CoV from any specimen and PCR confirmation using a validated method

ELISA = enzyme-linked immunosorbent assay; IFA = immunofluorescence assay; $\mathrm{PCR}=$ polymerase chain reaction; $\mathrm{RDS}=$ respiratory distress syndrome; SARS CoV = severe acute respiratory syndrome coronavirus. 
speaking, at presentation SARS is like CAP. Hence the management steps should consist of:

- prompt diagnostic procedures

- severity assessment

- use of broad spectrum antimicrobials, as with any CAP, until the infective agent is identified

- infection control measures (a pivotal role in management).

Further issues that may arise and need to be considered while patients are in hospital are discussed below.

\section{Respiratory support and procedures}

Procedures and practices that promote aerolisation should be avoided wherever possible to reduce the risk of infection to healthcare workers. These procedures include use of high-flow oxygen, nebulisers, continuous positive airway pressure, non-invasive ventilation, chest physiotherapy, bronchoscopy, tracheal intubation, suctioning and humidification. If essential, these procedures should be planned and controlled. ${ }^{51}$

Table 5. Management of severe acute respiratory syndrome (SARS) (adapted from the BTS/BIS SARS guidelines ${ }^{50}$ ).

\begin{tabular}{|c|c|c|c|c|}
\hline & \multicolumn{2}{|c|}{ Suspected SARS } & \multicolumn{2}{|c|}{ Probable SARS } \\
\hline & Non-severe & Severe & Non-severe & Severe \\
\hline Case definition & \multicolumn{2}{|c|}{$\begin{array}{l}\text { A person presenting after } 1 \text { Feb } 2003 \text { with all } 3 \text { : } \\
1 \text { High fever }>38^{\circ} \mathrm{C} \\
2 \text { Cough or breathing difficulty } \\
3-\mathrm{H} / \mathrm{o} \text { travel, to an area with local transmission } \\
\text { and/or } \\
- \text { Close contact with a person with probable SARS }\end{array}$} & $2 \mathrm{RDS}$ & o response to usual $\mathrm{Rx}$ \\
\hline Infection control issues & \multicolumn{2}{|c|}{$\begin{array}{l}\text { - N95 mask for patient to wear } \\
\text { - Consult in identified area away from others } \\
\text { - HCW to adhere to local infection control measures } \\
\text { (gown, gloves, mask, hand washing) } \\
\text { - Inform hospital infection control and CCDC }\end{array}$} & \multicolumn{2}{|c|}{$\begin{array}{l}\text { - Admit to negative pressure isolation room } \\
\text { - Transfer to regional centre } \\
\text { - Inform regional designated SARS ID unit }\end{array}$} \\
\hline Clinical issues & \multicolumn{4}{|c|}{$\begin{array}{l}\text { - Confirm travel/contact history + obtain history of close contact/household contacts } \\
\text { - Consider other causes of community acquired pneumonia } \\
\text { - Note comorbidity (severity risk) } \\
\text { - Assess severity (BTS guidelines) }\end{array}$} \\
\hline Investigative issues & \multicolumn{4}{|c|}{$\begin{array}{l}\text { - Laboratory testing for SARS (PHLS website): sputum, uri } \\
\text { - CXR } \\
\text { - Pulse oximetry and blood gases if } \mathrm{SpO}_{2}<92 \% \text { on air } \\
\text { - FBC, U\&E, LFT, LDH, CK, CRP } \\
\text { - Other microbiological samples (eg blood cultures) }\end{array}$} \\
\hline Treatment & $\begin{array}{l}\text { - Consider home } \\
\text { management } \\
\text { - Patient to record } \\
\text { temperature bd } \\
\text { - Daily medical review } \\
\text { (phone) } \\
\text { - Paracetamol for fever } \\
\text { - Fluids and bed rest }\end{array}$ & $\begin{array}{l}\text { - Admit to negative } \\
\text { pressure room/side room } \\
\text { or transfer } \\
\text { - Antibiotics as for severe } \\
\text { CAP ( } \beta \text {-lactam + } \\
\text { macrolide) } \\
\text { - Careful review } \\
\text { - Avoid CT scan }\end{array}$ & $\begin{array}{l}\text { - As for hospital } \\
\text { treated non-severe } \\
\text { CAP } \\
\text { - Oral amoxycillin + } \\
\text { macrolide } \\
\text { - Fluids and oxygen } \\
\text { as appropriate } \\
\text { - Observe closely for } \\
\text { change in clinical } \\
\text { status }\end{array}$ & $\begin{array}{l}\text { - Manage as for severe } \\
\text { CAP } \\
\text { - iv Co-amoxiclav or } \\
\text { cefuroxime + macrolide } \\
\text { - Oxygen flow rate } \\
>6 \mathrm{I} / \mathrm{min} \text { not } \\
\text { recommended } \\
\text { - Avoid procedures that } \\
\text { generate aerosols } \\
\text { - Critical care } \\
\text { - Steroids } \\
\text { - Ribavarin not } \\
\text { recommended }\end{array}$ \\
\hline Discharge & \multicolumn{4}{|c|}{$\begin{array}{l}\text { - Afebrile for } 48 \text { hours }+ \text { resolving cough }+ \text { lab tests returning to normal }+ \text { CXR improved } \\
\text { - Record temperature bd; if }>37.9^{\circ} \mathrm{C} \times 2 \text { report to healthcare facility } \\
\text { - Stay at home with minimum contacts for } 7 \text { days } \\
\text { - Follow-up at minimum of one week (? at home) } \\
\text { - Convalescent serology at } 3 \text { weeks }\end{array}$} \\
\hline
\end{tabular}

bd = twice daily; BTS = British Thoracic Society; CAP = community acquired pneumonia; CCDC = consultant in communicable disease control; CK = creatine kinase; $\mathrm{CRP}=\mathrm{C}$-reactive protein; $\mathrm{CT}=$ computed tomography; $\mathrm{CXR}=$ chest X-ray; EDTA = ethylene diamine tetraacetic acid; FBC = full blood count; HCW = healthcare worker; $\mathrm{H} / \mathrm{o}=$ history of; ID = infectious disease; iv = intravenous; LFT = liver function tests; LDH = lactate dehydrogenase; PHLS = Public Health Laboratory Service; $\mathrm{RDS}=$ respiratory distress syndrome; $\mathrm{Rx}=$ treatment; $\mathrm{SpO}_{2}=$ functional oxygen saturation (pulse oximetry); U\&E = urea $\&$ electrolytes. 


\section{Critical care}

Early intubation of patients with impending respiratory failure is preferred. ${ }^{52}$

\section{Steroids}

The biphasic nature of the illness and evidence from pathological studies suggest that steroids could prevent or ameliorate the rapidly progressive respiratory distress by modulating the cytokine dysregulation seen in the later stages of SARS. ${ }^{29}$ There is no evidence of any effect on mortality, but use of high-dose steroids has been reported to contribute to decrease in fever and the need for oxygen supplementation. ${ }^{53}$ These findings are not based on controlled data and there remains concern regarding the use of high-dose steroids, particularly risk of infection. ${ }^{54} \mathrm{~A}$ recent study has shown the superiority of pulsed steroids over daily treatment. ${ }^{55}$ The current recommendation is to consider moderate doses of steroids in severely ill patients with SARS with increasing oxygen requirements, with $\mathrm{PaO}_{2}$ below $10 \mathrm{kPa}$ or oxygen saturation below $90 \%$ on air.

\section{Ribavarin}

The evidence for the efficacy of ribavarin is lacking when used blindly in the early stages of the epidemic. In laboratory studies, no in vitro activity against SARS $\mathrm{CoV}$ has been demonstrated. Use of ribavarin is associated with a significant toxicity, including haemolysis (in about $76 \%$ of patients) and decrease in haemoglobin of $2 \mathrm{~g} / \mathrm{dl}$ (in about 49\%). ${ }^{56}$ Routine use of ribavarin in patients with SARS is therefore not currently recommended.

\section{Other treatments}

A variety of experimental treatments have been administered to patients with severe illness. The risk and benefits of each are currently not documented. They include:

- proteinase inhibitors

- intravenous immunoglobulins

- convalescent serum

- tumour necrosis factor alpha-blockers

- interferons ${ }^{57}$

- traditional Chinese medicines.

\section{Future}

\section{New drugs}

Are new drugs for SARS on the horizon? A Frankfurt team has shown that glycyrrhizin (derived from liquorice roots) can kill SARS virus cultured in monkey kidney cells. ${ }^{58}$ Another German group has recently identified the structure of a key SARS enzyme proteinase which plays a key role in viral replication. ${ }^{59}$ Using a computer model of this structure, they have begun to predict which drugs might inhibit the activity of the enzyme.

\section{Vaccination}

Will we have a vaccine to combat SARS? Vaccines already exist for animal coronaviruses; vaccine biologists are applying this expertise to SARS. ${ }^{60,61}$ Various techniques for vaccine development are being tried. One is targeted genetic modification of SARS virus whereby genes not needed for virus survival but required for it to cause disease are selectively deleted. Another approach uses genetically engineered harmless viruses which contain only those genetic sequences from the SARS virus that are necessary to stimulate the human immune system. This approach has been used to develop a prototype vaccine against a coronavirus that causes bronchitis in chickens. ${ }^{62}$

\section{Conclusions}

The sudden appearance of a pestilence like SARS is not without precedent, but what is remarkable is the speed with which the world's health community was ready to act in a coordinated way to develop specific diagnostic tests to identify and institute control measures which led to the control of the epidemic. ${ }^{63,64}$

This epidemic serves to confirm the continued threat of infectious diseases, of new infections to evolve and, above all, their global nature in the twenty-first century. It is to be hoped that the lessons learnt from this epidemic will provide a useful template with which to approach future epidemics of acute respiratory infections when they come along, as they surely will. Whether SARS will re-emerge as an epidemic infection is currently unknown.

\section{References}

1 Woodhead M, Ewig S, Torres A. Severe acute respiratory syndrome (SARS). Eur Respir J 2003;21:739-40.

2 World Health Organization Multicentre Collaborative Network for Severe Acute Respiratory Syndrome Diagnosis. A multicentre collaboration to investigate the cause of severe acute respiratory syndrome. Lancet 2003;361:1730-3.

3 Krause R. In: Morse SS (ed) Emerging infections. Foreword. Oxford: Oxford University Press, 1993.

4 Pearson H, Clarke T, Abbott A, Knight J, Cyranoski D. SARS: what have we learned? Nature 2003;424:121-6.

$5 \mathrm{Ng}$ SK. Possible role of an animal vector in the SARS outbreak at Amoy Gardens. Lancet 2003;362:570-2.

6 Fouchier RA, Kuiken T, Schutten M, van Amerongen G et al. Aetiology: Koch's postulates fulfilled for SARS virus. Nature 2003;423:240.

7 Peiris JS, Lai ST, Poon LL, Guan Y et al. Coronavirus as a possible cause of severe acute respiratory syndrome. Lancet 2003;361:1319-25.

8 Ksiazek TG, Erdman D, Goldsmith CS, Zaki SR et al. A novel coronavirus associated with severe acute respiratory syndrome. $N$ Engl J Med 2003;348:1953-66.

9 Drosten C, Gunther S, Preiser W, van der Werf S et al. Identification of a novel coronavirus in patients with severe acute respiratory syndrome. N Engl J Med 2003;348:1967-76.

10 Martina BE, Haagmans BL, Kuiken T, Fouchier RA et al. Virology: SARS virus infection of cats and ferrets. Nature 2003;425:915.

11 Rota PA, Oberste MS, Monroe SS, Nix WA et al. Characterization of a novel coronavirus associated with severe acute respiratory syndrome. Science 2003;300:1394-9.

12 Kuiken T, Fouchier RA, Schutten M, Rimmelzwaan GF et al. Newly 
discovered coronavirus as the primary cause of severe acute respiratory syndrome. Lancet 2003;362:263-70.

13 Marra MA, Jones SJ, Astell CR, Holt RA et al. The genome sequence of the SARS-associated coronavirus. Science 2003;300:1399-404.

14 Ruan YJ, Wei CL, Ee AL, Vega VB et al. Comparative full-length genome sequence analysis of 14 SARS coronavirus isolates and common mutations associated with putative origins of infection. Lancet 2003;361: 1779-85. Erratum: Lancet 2003;361:1832.

15 Brown EG, Tetro JA. Comparative analysis of the SARS coronavirus genome: a good start to a long journey. Lancet 2003;361:1756-7.

16 Yob JM, Field H, Rashdi AM, Morrissy C et al. Nipah virus infection in bats (order Chiroptera) in peninsular Malaysia. Emerg Infect Dis 2001;7: 439-41.

17 Zhong NS, Zheng BJ, Li YM, Poon LLM et al. Epidemiology and cause of severe acute respiratory syndrome (SARS) in Guangdong, Peoples' Republic of China, in February, 2003. Lancet 2003;362:1353-8.

18 Guan Y, Zheng BJ, He YQ, Liu XL et al. Isolation and characterization of viruses related to the SARS coronavirus from animals in Southern China. Science 2003;302:276-8.

19 WHO website. http://www.who.int/csr/sars/postoutbreak/en/

20 Donnelly CA, Ghani AC, Leung GM, Hedley AJ et al. Epidemiological determinants of spread of causal agent of severe acute respiratory syndrome in Hong Kong. Lancet 2003;361:1761-6. Erratum: Lancet 2003; 361:1832.

21 Lipsitch M, Cohen T, Cooper B, Robins JM et al. Transmission dynamics and control of severe acute respiratory syndrome. Science 2003;300:1966-70.

22 Riley S, Fraser C, Donnelly CA, Ghani AC et al. Transmission dynamics of the etiological agent of SARS in Hong Kong: impact of public health interventions. Science 2003;300:1961-6.

23 Seto WH, Tsang D, Yung RW, Ching TY et al. Effectiveness of precautions against droplets and contact in prevention of nosocomial transmission of severe acute respiratory syndrome (SARS). Lancet 2003; 361:1519-20.

24 Nicholls JM, Poon LL, Lee KC, Ng WF et al. Lung pathology of fatal severe acute respiratory syndrome. Lancet 2003;361:1773-8.

25 To KF, Chan PK, Chan KF, Lee WK et al. Pathology of fatal human infection associated with avian influenza A H5N1 virus. J Med Virol 2001;63:242-6.

26 Cheung CY, Poon LL, Lau AS, Luk W et al. Induction of proinflammatory cytokines in human macrophages by influenza A (H5N1) viruses: a mechanism for the unusual severity of human disease? Lancet 2002;360:1831-7

27 Li L, Wo J, Shao J, Zhu H et al. SARS-coronavirus replicates in mononuclear cells of peripheral blood (PBMCs) from SARS patients. J Clin Virol 2003;28:239-44.

28 Collins AR. Human macrophages are susceptible to coronavirus OC43. Adv Exp Med Biol 1998;440:635-9.

29 Peiris JS, Chu CM, Cheng VC, Chan KS et al; HKU/UCH SARS Study Group. Clinical progression and viral load in a community outbreak of coronavirus-associated SARS pneumonia: a prospective study. Lancet 2003;361:1767-72.

30 Tsang KW, Ho PL, Ooi GC, Yee WK et al. A cluster of cases of severe acute respiratory syndrome in Hong Kong. N Engl J Med 2003;348: 1977-85.

31 Poutanen SM, Low DE, Henry B, Finkelstein S et al; Canadian Severe Acute Respiratory Syndrome Study Team. Identification of severe acute respiratory syndrome in Canada. N Engl J Med 2003;348:1995-2005.

32 Lee N, Hui D, Wu A, Chan P et al. A major outbreak of severe acute respiratory syndrome in Hong Kong. N Engl J Med 2003;348:1986-94.

33 Booth CM, Matukas LM, Tomlinson GA, Rachlis AR et al. Clinical features and short-term outcomes of 144 patients with SARS in the greater Toronto area. JAMA 2003;289:2801-9. Erratum: JAMA 2003;290:334.

34 Fowler RA, Lapinsky SE, Hallett D, Detsky AS et al; Toronto SARS Critical Care Group. Critically ill patients with severe acute respiratory syndrome. JAMA 2003;290:367-73.

35 Leung WK, To KF, Chan PK, Chan HL et al. Enteric involvement of severe acute respiratory syndrome-associated coronavirus infection. Gastroenterology 2003;125:1011-7.

36 Lew TW, Kwek TK, Tai D, Earnest A et al. Acute respiratory distress syndrome in critically ill patients with severe acute respiratory syndrome. JAMA 2003;290:374-80.

37 Wong RS, Wu A, To KF, Lee $\mathrm{N}$ et al. Haematological manifestations in patients with severe acute respiratory syndrome: retrospective analysis. BMJ 2003;326:1358-62.

38 Goh JS, Tsou IY, Kaw GJ. Severe acute respiratory syndrome (SARS): imaging findings during the acute and recovery phases of disease. J Thorac Imaging 2003;18:195-9.

39 Grinblat L, Shulman H, Glickman A, Matukas L, Paul N. Severe acute respiratory syndrome: radiographic review of 40 probable cases in Toronto, Canada. Radiology 2003;228:802-9.

40 Wong KT, Antonio GE, Hui DS, Lee $\mathrm{N}$ et al. Severe acute respiratory syndrome: radiographic appearances and pattern of progression in 138 patients. Radiology 2003;228:401-6.

41 Muller NL, Ooi GC, Khong PL, Nicolaou S. Severe acute respiratory syndrome: radiographic and CT findings. AJR Am J Roentgenol 2003; 181:3-8.

42 Wong KT, Antonio GE, Hui DS, Lee $\mathrm{N}$ et al. Thin-section CT of severe acute respiratory syndrome: evaluation of 73 patients exposed to or with the disease. Radiology 2003;228:395-400.

43 Antonio GE, Wong KT, Hui DS, Wu A et al. Thin-section CT in patients with severe acute respiratory syndrome following hospital discharge: preliminary experience. Radiology 2003;228:810-5.

44 Tanaka N, Matsumoto T, Kuramitsu T, Nakaki $\mathrm{H}$ et al. High resolution CT findings in community-acquired pneumonia. J Comput Assist Tomogr 1996;20:600-8.

45 Tsui PT, Kwok ML, Yuen H, Lai ST. Severe acute respiratory syndrome: clinical outcome and prognostic correlates. Emerg Infect Dis 2003, 9:1064-9.

46 Chan JW, Ng CK, Chan YH, Mok TY et al. Short term outcome and risk factors for adverse clinical outcomes in adults with severe acute respiratory syndrome (SARS). Thorax 2003;58:686-9.

47 Hon KL, Leung CW, Cheng WT, Chan PK et al. Clinical presentations and outcome of severe acute respiratory syndrome in children. Lancet 2003;361:1701-3.

48 Poon LL, Chan KH, Wong OK, Yam WC et al. Early diagnosis of SARS coronavirus infection by real time RT-PCR. J Clin Virol 2003;28:233-8.

49 Rainer TH, Cameron PA, Smit D, Ong KL et al. Evaluation of WHO criteria for identifying patients with severe acute respiratory syndrome out of hospital: prospective observational study. BMJ 2003;326:1354-8.

50 BIS/BTS SARS Guideline July 2003. Website. http://www.brit-thoracic.org.uk/docs/Sars\%20guidance\%20ver\%203Jul2003.doc.

51 Li TS, Buckley TA, Yap FH, Sung JJ, Joynt GM. Severe acute respiratory syndrome (SARS): infection control. Lancet 2003;361:1386.

52 Lapinsky SE, Hawryluck L. ICU management of severe acute respiratory syndrome. Intensive Care Med 2003;29:870-5.

53 So LK, Lau AC, Yam LY, Cheung TM et al. Development of a standard treatment protocol for severe acute respiratory syndrome. Lancet 2003 361:1615-7.

54 Wang H, Ding Y, Li X, Yang L et al. Fatal aspergillosis in a patient with SARS who was treated with corticosteroids. N Engl J Med 2003;349: 507-8.

55 Ho JC, Ooi GC, Mok TY, Chan JW et al. High-dose pulse versus nonpulse corticosteroid regimens in severe acute respiratory syndrome. Am J Respir Crit Care Med 2003;168:1449-56.

56 Knowles SR, Phillips EJ, Dresser L, Matukas L. Common adverse events associated with the use of ribavirin for severe acute respiratory syndrome in Canada. Clin Infect Dis 2003;37:1139-42.

57 Cinatl J, Morgenstern B, Bauer G, Chandra P et al. Treatment of SARS with human interferons. Lancet 2003;362:293-4. Erratum: Lancet 2003;362:748.

58 Cinatl J, Morgenstern B, Bauer G, Chandra P et al. Glycyrrhizin, an active component of liquorice roots, and replication of SARS-associated coronavirus. Lancet 2003;361:2045-6. 
59 Anand K, Ziebuhr J, Wadhwani P, Mesters JR, Hilgenfeld R. Coronavirus main proteinase (3CLpro) structure: basis for design of anti-SARS drugs. Science 2003;300:1763-7.

60 De Groot AS. How the SARS vaccine effort can learn from HIV speeding towards the future, learning from the past. Vaccine 2003; 21:4095-104.

61 Schlagenhauf P. Influenza vaccine enlisted to prevent SARS confusion. Lancet 2003;362:809.

62 Johnson MA, Pooley C, Ignjatovic J, Tyack SG. A recombinant fowl adenovirus expressing the $\mathrm{S} 1$ gene of infectious bronchitis virus protects against challenge with infectious bronchitis virus. Vaccine 2003; 21:2730-6.

63 Snijder EJ, Bredenbeek PJ, Dobbe JC, Thiel V et al. Unique and conserved features of genome and proteome of SARS-coronavirus, an early split-off from the coronavirus group 2 lineage. J Mol Biol 2003; 331: 991-1004.

64 Enserink M, Vogel G. Infectious diseases. Deferring competition, global net closes in on SARS. Science 2003;300:224-5. 